\title{
UM CONCEITO DE EQUIVALÊNCIA NA EXPRESSÃO VERNÁCULA DA POESIA LATINA
}

\author{
João Batista Toledo Prado
}

\begin{abstract}
RESUMO: Taking Joseph Brodsky's concept of “equivalence” as far as translating foreign poems into literary forms plausible to the translator's mother tongue and culture, this paper offers a possible application of that concept to the latin love elegy lesser constituent unit, the elegiac couplet, and on the prosodic elements peculiar to the metres which it is made up of: the hexametre and the pentametre. The intention here is to study the poetic nature of the latin love elegy, through the latin linguistic system characteristics which provide the very basis for its metrical poetic system. That posture has driven us to a revaluation of the latin metric system through the prism of linguistic investigation, on all that concerns at least the elegiac couplet and its prosodic specificities, what has allowed to uncover an entire new range of possibilities to reading elegiac expressivity, as it was attempted to show with one exemple taken from the roman elegiac poet Tibullus, from the century I b. C.
\end{abstract}

PALAVRAS-CHAVE: Brodsky, equivalência, poética clássica, tradução, métrica latina, dístico elegíaco, ritmo, plano de expressão, elegia, Tibulo.

O lapso de tempo que separa as sociedades modernas daquelas que produziram todos os artefatos culturais da antigüidade clássica, artefatos sobre os quais os pesquisadores do presente nos debruçamos, na tentativa de desvendar o que quer que seja de seus mecanismos de produção e de funcionalidade, de modo invariável cria dificuldades que só podem ser solucionadas seja por meio de novos dados, continuamente redescobertos, no mais das vezes pelos especialistas em cultura material, seja por ecos eventuais de testemunhos diretos (o que é praticamente impossível em se tratando do caráter literário dos textos sobreviventes) seja ainda com o aprofundamento da reflexão filosófica, promovida pela concorrência do pensamento crítico e do avanço da ciência moderna.

Se isso é verdade para todas as áreas do saber preocupadas com os povos do passado clássico, com mais forte razão, os pesquisadores da linguagem deverão servir-se de todos os expedientes a seu alcance, no intuito de melhor compreenderem as culturas antigas, por meio do estudo das línguas que as constituíram. É nesse meio que se inserem os latinistas que, por força do ofício, vêem seus esforços continuamente dirigidos a tentar recuperar o maior número possível de informações através de "traduções" de textos latinos para o vernáculo.

A tarefa de traduzir os clássicos, ainda que meritória porque tenta saldar uma parte do que Hjelmslev, ao falar da ciência, chamou de a dívida para com o homem e a sociedade (HJELMSLEV, 1971, p. 104), nem sempre é colmada de êxito, seja por criar um texto que, embora se sustente em vernáculo, difere muito do original, porque transfigurado tanto na expressão quanto no conteúdo, seja por subtrair ao original justamente aqueles dados expressivos essenciais à sua natureza, o que compromete o alcance da leitura moderna que dele se faz, no tocante ao caráter que tinha o texto original no seio da cultura que o viu surgir.

João Batista Toledo Prado é professor da Faculdade de Ciências e Letras da UNESP - Campus de Araraquara - SP. 
No âmbito dos estudos da linguagem, feitos sobre a cultura da Roma antiga, o caso mais significativo a esse respeito é, talvez, o da poesia latina, cujos textos, a despeito dos restritos preceitos métricos com que são construídos e, mais, dos seus artifícios de expressividade, têm sido alvo de traduções em prosa, em que se presta conta, em geral, apenas da substância (quando muito da forma) do conteúdo do texto, com ônus evidente para o plano de expressão, em que não é mais possível reconhecer um poema.

Sabe-se, no mais, que a leitura sempre desempenhou papel crucial na vida das obras literárias do mundo clássico, desde sua concepção até sua difusão nas camadas cultas da sociedade a que se destinavam, de maneira a ser lícito afirmar que não se concebiam peças literárias sem que houvesse, por pressuposto primeiro, manifesto intento de que as experiências estéticas que propiciavam fossem atingidas com e através da leitura.

O problema da leitura se torna ainda maior, quando se tem em mente o fato de que os poemas latinos eram compostos com o propósito de serem reenunciados de forma oral, isto é, lidos em voz alta, como o atestam numerosos depoimentos de autores latinos como Cícero e Quintiliano, o que revela um alto grau de comprometimento entre os cuidados formais do plano de expressão e o modo de recepção da audiência. Nesse sentido, traduzir, ou seja, resgatar vozes do passado, de uma língua que deu sustentação a uma cultura há muito desaparecida, pode parecer insensato ou, pelo menos, temerário, pois como lembrou recentemente um autor moderno, ao falar da escrita em Roma, Devolver voz aos textos é uma operação delicada. Ainda mais quando se trata de textos antigos, quando a distância é maior entre aquele que escreveu um texto e aquele que o lê (DESBORDES, 1990, p. 223).

A tarefa se torna possível, no entanto, se se adotarem princípios capazes de respeitar o plano de expressão, até onde isso seja possível, sem distanciar-se muito do original nem desfigurar o idioma materno, e atentando para as correspondências formais que possam ser encontradas, na prática literária de uma e de outra cultura.

Como se trata, todavia, de apreciar o plano de expressão dos poemas latinos, será preciso reconhecer que, à semelhança do que ocorreu com as pesquisas lingüísticas pré-saussurianas de cunho comparatista, cujo objetivo era o de estudar e explicar as línguas, mas que ficaram sempre à margem de sua natureza, por trabalhar com dados saltuários e externos, também a Poética e, em particular, sua vertente de Métrica Latina sempre trabalharam com os disiecta membra do verso e "atomizaram" cada vez mais os dados que a pesquisa, assim conduzida, descobria na poesia. A causa disso é que não levaram em conta que, ao ocupar-se de uma modalidade de arte que utiliza a linguagem como matéria-prima, deveriam ocupar-se também dos mesmos princípios que norteiam a linguagem verbal e tornam possível explicar os fenômenos dela oriundos.

O inconveniente de semelhante modo de encarar os objetos da linguagem tem como fundamento a idéia, tão superficial quanto ingênua, de que a língua é uma espécie de esteio, de instrumento ${ }^{1}$, como tantos outros forjados pela necessidade e pela inventividade humanas, quando, na verdade, a partir de Saussure, a língua passa a ser entendida como sistema internalizado e consubstancial ao homem, vale dizer, como algo que, nas palavras de Benveniste e na sequiência de Saussure, define o próprio homem: Não atingimos jamais o homem reduzido a si mesmo e procurando conceber a existência do outro. É um homem falando que encontramos no mundo, um homem falando com outro homem, e a linguagem ensina a própria definição do homem. (BENVENISTE, 1991, p. 285.).

E homem, aqui, não é apenas o designativo genérico da espécie, amplo demais e, por isso, correndo sempre o risco de mesclar-se a novas abstrações, e sim, sobretudo, o psiquismo de cada um, pois psiquismo e faculdade da fala são praticamente a mesma coisa. É uma ilusão separá-los, como adverte ainda Benveniste: A sociedade não é possível a não ser pela língua; e, pela língua, também o indivíduo. $O$ despertar da consciência na criança coincide sempre com a aprendizagem da linguagem, que a introduz pouco a pouco como indivíduo na sociedade. (Ibidem, p. 27.).

$\mathrm{Na}$ realidade, não são só os humanistas que têm essa concepção, pela qual se pensa que a palavra é uma espécie de símbolo ou repraesentamen da coisa significada, algo que se confunde com a própria substância fônica ouvida tanto quanto com a substância escrita. Pensar assim é praticar uma antidialética, porque condenar-se à não superação do conceito implicado pelo dia- que define o termo:

\footnotetext{
${ }^{1}$ A esse respeito, convém recordar quão lamentável que já se tenha pensado e escrito que [...] a dicotomia apresentação/representação, aplicada ao território literário, dê resultados tão pobres. A ponto de se poder perguntar se a sua interpretação seria precisamente a que convém ao campo literário e se ela não se enquadraria melhor no que é para a literatura um mero material [grifo nosso], isto é, a linguagem. (TODOROV, 1980, p. 122).
} 
opõe-se uma tese a uma antítese, sem se chegar à síntese, que é o objetivo do processo dialético.

Essa concepção não está de forma alguma superada nem mesmo nos dias que correm. Basta que se recordem os "desvios" e as "ambigüidades" da língua ${ }^{2}$, o tratamento dado a escritores com especial sensibilidade para a dimensão falada do idioma (como Guimarães Rosa ${ }^{3}$ ), tratamento que parece considerá-los como que fabricantes de uma outra língua, para ver o quanto ainda resta a ser entendido apropriadamente, ou seja, à luz das ciências da linguagem, às quais tais designações não fazem sentido.

Tudo o que normalmente se alinha sob um feixe de fenômenos rotulado de "desvio" se explica, e bem, se lembrarmos, por exemplo, que até mesmo onomatopéias como tilintar ou ronronar são verbos tão arbitrários em sua porção léxica quanto qualquer outro termo não-motivado da língua, no que tange à relação significante-significado. E, mais, que as chamadas "interjeições" não são palavras ao mesmo título que as outras classes de palavras, pois não é, por exemplo, ai!, que significa dor, mas a espécie de gesto vocal, realizado com toda a sorte de traço supra-segmental, tal como o timbre e a intensidade, que se lhe imprimem ao articulá-lo, que constitui o sinal da dor que se sente, e não a idéia da dor concebida e depois expressa verbalmente, como é feito quando se diz está doendo...; está doendo são palavras, ai, não. Tal fato já havia sido apontado, pelo menos, por Jakobson:

$\mathrm{O}$ estrato puramente emotivo da linguagem é apresentado pelas interjeições. Estas diferem dos procedimentos da linguagem referencial [...] pela sua configuração sonora (seqüências sonoras peculiares ou mesmo sons alhures incomuns). [...] A função emotiva, evidenciada pelas interjeições, colore, em certa medida, todas as nossas manifestações verbais, ao nível fônico, gramatical e lexical. (JAKOBSON, 1985, p. 124).

As palavras se prestam, pois, a empregos lúdicos, comuns e caros tanto às crianças quanto aos poetas, sejam tais jogos experiências verbais pueris (simples repetição mecânica de sílabas, como papá e mamã, em que estão embutidas as primeiras experiências de expressão da afetividade humana, compartilhadas por todas as culturas, porque próprias de todo o gênero humano, e por meio das quais se efetiva aquela memorável exortação virgiliana: Incipe, parue puer, risu cognoscere matrem (Bucólicas, IV, 60), Principia, filho, rindo,/ a reconhecer tua mãe//); sejam os dos subidos refinamentos metafóricos, como faz notar Huizinga: Por trás de toda expressão abstrata se oculta uma metáfora, e toda metáfora é jogo de palavras. Assim, ao dar expressão à vida, o homem cria um outro mundo, um mundo poético, ao lado do da natureza. (HUIZINGA, 1971, p. 7).

E é mesmo possível afirmar que há muito em comum entre as experiências verbais das crianças e as metáforas praticadas pelos poetas, em que se verifica como que uma retomada ou apelo às livres associações e aproximações entre termos sem qualquer parentesco etimológico ${ }^{4}$, mas que compartilham algum traço comum, quer meramente fonético quer de ordem semântica:

Metáfora e gesticulação fonética atestam a existência de uma camada não revelada pelos signos arbitrários, que não têm relação direta com a experiência individual, uma camada profunda por onde se estabelece uma outra forma de comunicação verbal. O poeta, o trovador, o fabricante de tropos (tropator) retorna por um instante a um estado anterior à linguagem, por meio de uma regressão até a infância (infans: o indivíduo que ainda não fala). (FÓNAGY, I., Le langage poétique: forme et fonction. In: BENVENISTE, 1966, p. 98.).

Os empregos metafóricos de termos envolvendo o som, ou metáforas fonéticas como as chamou Fónagy, por mais motivações expressivas que simulem, nunca deixam de ter um plano lingüisticamente verbal não motivado, que faculta entender a operação lúdica que lhes confere um novo estatuto, homologável aos mesmos procedimentos do plano denotado. A versificação é dessa natureza, por mais que reaproveite o som (vocálico ou consonântico) para re-significar "imitativamente" este ou aquele conceito.

\footnotetext{
${ }^{2}$ Cf. a esse respeito, por exemplo, GUIRAUD, P., Problèmes et méthodes de la statistique linguistique, p. 19 et seq.

${ }^{3}$ Cf., por exemplo, in: GUIMARÃES ROSA, J., Ficção completa, v. 1, os termos com que se referem esses autores à ficção rosiana (os grifos são nossos): “desintegração da sintaxe tradicional [...]” " e "os efeitos [...] dessa subversão [...]" (GERSEN, B., Veredas no Grande Sertão, p. 105), "a desarticulação da linguagem" (Idem, p. 106); "Essas complexidades formais, esses embaraços de composição [...]" (MONTENEGRO, B., Guimarães Rosa, novelista, p. 150), "estilo [...] altamente pessoal [...]" (Idem, p. 163; vide tb. seq.).

${ }^{4}$ Os poetas sugerem, por vezes, etimologias sem qualquer lastro na história objetiva da língua, para trazer à consciência certas associações oriundas da impressão de parentesco que pode haver entre elas, porque Tais etimologias poéticas têm estreita relação com o tratamento preconsciente ou mesmo inconsciente dado às palavras e com a revalorização de elementos lingüísticos discretos ou latentes, que se encontram tão freqüentemente no calembur ou no sonho. (FÓNAGY, I., Le langage poétique: forme et fonction. In: BENVENISTE, 1966, p. 106).
} 
Com tais considerações em mente, pode-se, enfim, precisar que o objetivo deste artigo, longe de tentar resolver imediatamente o problema, é encaminhar uma proposta de tradução, que se caracterize pelo enfrentamento das dificuldades expressivas dos poemas latinos, através do emprego da idéia de equivalência, como a formulou Joseph Brodsky: A tradução é a procura de um equivalente, e não de um substituto. Requer pelo menos uma afinidade estilística, quando não, psicológica.( BRODSKY, 1994, p. 84.).

Isso significa que, em proveito da idéia de equivalente, é preciso abandonar a idéia de substituto vernáculo do texto original, em que se procura uma formulação textual em língua materna, que desconsidera os traços essenciais do original e de seu compromisso com a cultura que o originou, criando assim uma realidade independente e que, por isso mesmo, não pode ser chamada de tradução. Ao contrário, é preciso buscar na língua e na cultura maternas expressões histórica, literária e lingüisticamente plausíveis para reproduzir, tanto quanto possível e de uma só vez, ou seja, com a unidade que caracteriza um texto como tal, ainda mais um texto poético, reproduzir a unidade, dizia-se, da forma do conteúdo e da forma da expressão associadas no texto de origem, capazes de gerar os efeitos de sentido provocados pelo texto, latino no presente caso.

Para chegar a tal propósito, pretende-se aqui cerrar fileiras em torno da afirmação brodskiana de que a tradução é a busca de um equivalente para tentar conferir-lhe estatuto de conceito operatório no empreendimento da tradução.

Um primeiro passo seria perguntar: se a tradução consiste em procurar equivalentes, procurar-se-iam equivalentes de quê? Certamente não de termos isolados, nem tampouco das frases latinas simplesmente transpostas para o idioma materno, visto que um texto não é apenas a somatória de cada uma das unidades frasais que o constituem. Um texto e, sobretudo, um texto poético caracteriza-se antes por aquela que parece ser a única lei universal da poesia, qual seja, a da isomorfia que parecem atingir os dois planos da linguagem verbal, o do conteúdo e o da expressão, os quais, fazendo convergir o seus recortes formais para uma forma única e indissociável, provocam no receptor o reconhecimento de que a mensagem é de uma natureza tal em que predomina a função poética da linguagem, no sentido jakobsoniano do termo (cf. JAKOBSON, 1985, p. 122 et seq.). Isso provoca a distinção com que normalmente se apregoa ser um texto poético de fato ou, ao contrário, tratar-se daqueles que, usando de recursos característicos da Poética, tais como a versificação, tão cara a toda poesia clássica, simplesmente contêm idéias em versos, porque, como se sabe,

não basta a versificação para fazer a verdadeira poesia, como já ensinava Aristóteles: "Se alguém publica, em versos, algum tratado de medicina ou de ciência natural, chamamo-lo por hábito poeta. Mas na verdade não há nada em comum entre Homero e Empédocles, à exceção do verso; e por isso àquele seria justo chamá-lo poeta, a este, ao contrário, não poeta mas fisiólogo." (PERINI, G. B. Fondamenti di metrica. In: TRAINA, A., PERINI, G. B., 1982, p. 203.).

A segunda questão consiste em entender o que pode significar afinidade estilística, quando não, psicológica. A natureza de uma tal afinidade se obtém, parece, mais uma vez com a forma do texto e não com a sua substância, pois afinidade estilística diz respeito à forma com que se engendram as frases poéticas e todos os recursos lingüísticos de que dispõe o sistema da língua, acrescidos dos que são fornecidos pelo sistema poético e retórico, entram aí. Já a afinidade psicológica diz respeito àqueles recursos expressivos que geram uma certa "impressão de realidade" que são os efeitos de sentido empregados no texto, como foram definidos por Greimas e Courtés (GREIMAS, A. J., COURTÉS, J., 1983, p. 136-7.).

A afinidade psicológica também pode se resolver no mecanismo de recepção da função poética do texto, concebida, uma vez mais, como unidade entre forma e conteúdo, em sua relação com o psiquismo humano. Esse fato foi estudado por Ivan Fónagy (FÓNAGY, op. cit., p. 100.) e enunciado sob a forma da seguinte relação de proporcionalidade:

\begin{tabular}{lll} 
Forma & $::$ & Inconsciente \\
\hline Conteúdo &
\end{tabular}

Sobre a percepção pré-consciente da forma dos signos, trabalhada pela poesia, diz também o autor, na mesma passagem, que

é difícil imaginar alguma coisa oculta na superfície; uma mensagem oculta que seja a própria superfície. A chave do enigma se prende, creio, à própria natureza dos signos lingüísticos. Os 
signos lingüísticos não são percebidos enquanto signos, senão por referência a outros objetos. Isso quer dizer que o signo não pode funcionar, não pode existir como mero signo, uma vez que ele não tem existência própria. Nossa atenção se desvia do signo no instante de sua articulação, e não considera senão o fonema, e do fonema nossa atenção se transporta ao morfema, e de lá até a frase, e da frase ao contexto, à situação em que a frase se insere e que ela implica. $\mathrm{O}$ mimetismo vocal está oculto, deformado pelo fonema (enquanto conjunto de signos característicos); e não raro a significação do morfema não ultrapassa a soleira crítica do pensamento consciente [...]. O calembur dá testemunho de que o sentido primeiro dos morfemas está preservado no nível do pensamento subconsciente [...]. Na vida quotidiana, não prestamos senão uma fraca atenção às metáforas latentes que as expressões mais familiares contêm. (Ibidem, p. 100-1.).

Não seriam mecanismos desse tipo a que os melhores poetas de todos os tempos sempre souberam estar atentos, quando tiraram de suas forjas o brilho de versos que atingiram a glória da imortalidade, alguns mesmo incorporando-se ao repertório dos provérbios? Pense-se, por exemplo, naqueles célebres e já tão repisados versos do Mar Portuguez de Pessoa: Valeu a pena? Tudo vale a pena I Se a alma não é pequena, em que o recurso da rima põe em relevo aquilo sobre que o poeta quer chamar a atenção de seu leitor/ouvinte, no caso, a frase impessoal "valer a pena", retomada no segundo hemistíquio, aparentemente como predicado, uma vez que a condição de sujeito foi preenchida; no entanto, o foi por meio de um indefinido "tudo". O segundo verso, em que o sujeito é preenchido por "alma", um nome cujo sentido cultural chega quase a fazer eco à extensão do indefinido "tudo", acrescenta um sinal de condição negativa "se...não" mais verbo copulativo e o adjetivo predicativo "pequena", que devolve o poema, nesse passo, ao verso anterior, resolvendo-lhe a questão da simetria dos hemistíquios do primeiro verso, bem como das rimas finais, mais uma rima interna, e dando-lhe o tom lúdico que, nos adverte Huizinga (HUIZINGA, op. cit., p. 7.), deve possuir toda poesia: se a alma não é pequena, segundo o poeta, resta-lhe ser, talvez, menos que "pequena", por exemplo, tomando-lhe uma sílaba da emissão, justamente a sílaba medial, o resultará um outro vocábulo, "pena", que não tem no poema existência independente mas, sim, vinculada ao sintagma "valer a pena" e, assim, o poema faz como que uma demonstração formal de seu conteúdo, da maneira mais singela e simples, mais "natural", quase pueril, atingindo a pretendida unidade entre forma e conteúdo como só grandes poetas sabem fazer.

E já que chegamos ao momento de discutir poemas, passemos sem demora ao poema latino com que pretendemos ilustrar o conceito de equivalência na tradução. A demonstração desse conceito far-se-á por meio do exame de uma pequena passagem de Tibulo, um trecho de poema, de fato, composto em dístico elegíaco, isto é, um hexâmetro e um pentâmetro datílico, seguido de uma tradução de serviço ou nota ou, ainda, comentário vernáculo ao texto latino, e de uma confrontação com uma tradução que procurou se pautar pelas idéias sobre as quais se discorreu aqui.

A questão de expressividade poética que discutiremos na passagem de Tibulo diz respeito ao aproveitamento, na tradução, de um dos aspectos do plano de expressão dos poemas, o de sua sonoridade ou, mais precisamente, a de suas metáforas fonéticas, como as chama o já citado Fónagy. Antes, porém, de apresentarmos o dístico, é conveniente lembrar que os empregos metafóricos de termos envolvendo o som, por mais motivações expressivas que simulem, nunca deixam de ter um plano lingüisticamente verbal não motivado, que faculta entender a operação lúdica que lhes confere um novo estatuto, homologável aos mesmos procedimentos do plano denotado. A versificação é dessa natureza, por mais que reaproveite o som (vocálico ou consonântico) para re-significar "imitativamente" este ou aquele conceito.

Assim, no dístico:

Hic ueniat Natalis auis prolemque ministret,

ludat et ante tuos turba nouella pedes,

(TIBULLE II, 2, 21-22. In: PONCHONT, 1950, p. 92)

cuja tradução de serviço, que procura ser o mais literal possível, apta somente a propiciar ao leitor um cotejo proveitoso do original latino, sem, no entanto, descurar dos preceitos de organização da frase portuguesa, poderia ser esta:

Aqui venha o Gênio Natal e aos avós dê uma prole,

e essa jovem turba brinque diante de teus pés,

e cuja tradução propriamente dita, isto é, aquele texto que se oferece em vernáculo como uma tentativa de produzir um equivalente brodskiano do poema que se está tentando trazer à vida e à cultura maternas, ficasse, quem sabe, bem acomodada assim: 
Que venha o Gênio e aos avós dê netos,

jovem turba em tropel diante de ti,

pode-se constatar que se tentou oferecer um texto poético vazado em decassílabos que, se têm o defeito de não reproduzir de modo tão imediato a variação métrica, isto é, o andamento rítmico, quanto supomos fosse o caso de sua percepção por parte dos ouvintes romanos, terá decerto o benefício de ser reconhecido imediatamente como verso em português, língua de uma cultura que dispõe, ademais, de outros recursos para a variação rítmica, como, por exemplo, a acentuação métrica: Quel ve'|nhaN ol Gế'|niol e $\mathrm{N}$ aols $\mathrm{N}$ alvós'| dêl ne'|tos, /jo'|vem| tur'|ba $\mathrm{N}$ em| trolpel'| dian|tel del ti'll.

Por mais que se afirme ouvir aí o tropel da chusma dos netos diante dos avós, isso nada tem a ver com os pá, pá, pá e tum, tum, tum, com que se costumam simular, no discurso, as pancadas disferidas contra alguém ou contra algo, no que concerne a esse som ou sílaba três vezes emitida, que não significa, isto é, não realiza a relação significante vs. significado, porque tais sons simplesmente "reproduzem" vocalmente, em intenção inconfundível, determinados gestos, quaisquer que sejam, tal como se poderia fazer, por exemplo, aplicando, de fato, tapinhas nalgum circunstante ou golpes, com os nós dos dedos, contra um tampo de mesa, com a intenção de representar visualmente para um interlocutor, um acontecimento narrado.

Nem pá, pá, pá ou tum, tum, tum, nem os tapas ou pancadas com os nós dos dedos constituem língua, no sentido saussuriano. Uns e outros continuarão meros códigos enquanto não adquirirem o estatuto competencial da criatividade e da produtividade, no sentido que os termos adquiriram em lingüística moderna ${ }^{5}$, ou seja, enquanto não se constituírem termos dicionarizáveis da língua (no sentido comum).

Só são dicionarizáveis, na verdade, termos que comportarem, com as léxicas, indicações morfossintáticas referentes à oração: substantivo, artigo, adjetivo, pronome, verbo, advérbio, preposição, numeral e conjunção. É bom notar que a interjeição não cabe aí ao mesmo título que as outras nove, e não cabe porque não faz parte da oração, que é, em suma, a unidade da língua. Versos também são unidades da língua, no entanto, não se dicionarizam, como não se dicionarizam onomatopéias, por mais usuais que sejam. É só forçando critérios que se consignam neles coisas com essa "classificação".

Caberia perguntar, portanto, como é que se ousa dizer aqui que métrica tem que ser tratada formalmente como língua. O que aqui se afirma, com toda força de que se é capaz, não é que métrica seja língua, e sim que tudo aquilo que se expressa com a língua recebe vida de língua, isto é, da psique, da percepção lingüística que faculta unificar seqüências de sílabas em sistemas, pois não se pode estudar nada referente à língua e à linguagem sem que se dispense ao assunto o mesmo tratamento dado aos fatos da linguagem.

Assim, as recorrências cumulativas de oclusões dentais, combinadas com as velares, de Tibulo II, 2, 21-2, legitimam-se como poesia latina no sistema da língua latina. Se não fosse possível identificá-las e analisá-las, léxico-morfossintático-fonologicamente como latim, isso não seria poesia latina nem de outra ordem qualquer, porque o que faz tais sequiências terem algum estatuto é a língua de Roma. O sentido e o efeito de sentido que ali se notam são língua de Roma!

Não é por diferente razão que a análise métrica independente que se queira fazer desses artefatos resulta um imenso desastre, como são aqueles que os tratados de métrica e os procedimentos preocupados com fatos de substância da linguagem, mesmo os de encaminhamento mais recente, perpetraram, pelo simples fato de que desconsideraram a língua, ou antes, apartaram a métrica da língua.

Para explorar uma analogia musical, tão comum como quando se fala da melodia de um poema, fica tudo como se se quisesse fazer uma música, marcando o tempo com símbolos indicadores de duração dos compassos, de duração das notas, mas não se indicasse o intervalo entre eles, isto é, não se oferecesse a chave da melodia que soou na percepção de quem a quis escrever. A melodia está para a música como a oração está para o sentido. O intervalo da analogia buscada com a música são as classes de palavra que permitem perceber as relações oracionais com base no nome e no verbo.

Se se chega a perceber, por analogia e não por convenção social, semelhanças entre inquietação, turbulência pueril e a recorrência de dentais (ainda no Tibulo aqui transcrito) é porque existem termos

\footnotetext{
${ }^{5}$ Os conceitos referidos evocam a capacidade humana, contida em cada língua particular e, portanto, na linguagem em geral, de produzir, com um número finito de possibilidades combinatórias, um número potencialmente infinito de enunciados. A recorrência das estruturas originadas pelas propriedades combinatórias são ditas produtivas, quando ocorrem a cada vez num novo enunciado, fruto da qualidade criativa da língua (cf. CRYSTAL, s.v. Criatividade, 1988, p. 71).
} 
arbitrariamente cunhados com dentais, como o $/ t /$, que expressam, sempre arbitrariamente e por pura convenção, esses sentidos. A não ser dessa forma, ou seja, se não existir a eventualidade fortuita da ocorrência ocasional de termos assim na língua, não há poeta, artesão de palavras, que os faça surgir.

Os elementos do sistema quer fonológico, quer morfossintático, são sempre pouco numerosos e, portanto, apresentam sempre alto índice de recorrência. É o que salva o poeta e sua expressão mais ou menos voltada para os efeitos de tipo analógico e rítmico. Entram aí as questões de métrica e de poética em geral, no seio das quais se devem lembrar aquelas determinações extralingüísticas, mas que acabam por incorporar-se à vida dos idiomas ${ }^{6}$, em razão do prestígio que alguns dos seus falantes bem dotados passam a gozar junto às elites. Ou, quem sabe, o que deve ser levado em conta aí é só o talento verbal de um Lucrécio e de um Virgílio?

Embora seus textos continuem a ser simples ocorrências e não a própria língua, do ponto de vista da expressão eles são definitivos na afirmação dos idiomas, que não seriam o que são sem esses poetas. Não importa. Do ponto de vista da teoria, eles são ocorrências, flutuações, diante da constante que é a língua. Estudá-los implica conhecimento do sistema, e é à luz deste que eles devem ser apreciados.

Pode-se, assim, sustentar que o princípio saussuriano de arbitrariedade do signo é indispensável ao princípio da forma, necessário, por sua vez, ao estabelecimento de conceitos operatórios, presentes também quando se fala de analogia e não de mera convenção presente na significação denotada. A localização de figuras analógicas nunca toma a dianteira. É assim que se torna possível, sem contradição, encarar tudo que é lúdico em matéria de linguagem.

O tropel dos netinhos tibulianos, aliás, só é digno de nota porque está expresso em língua latina, antes de o estar em dístico, em aliteração e em assonâncias que podem apor-se às aliterações. É claro que não se dispensa o talento, mas se a língua latina não oferecesse essas possibilidades, não haveria Tibulo que conseguisse produzir esses efeitos. Ou seja, a distância entre o social (a langue) e o individual (a parole) é difícil de ser avaliada nos devidos termos.

Pensando ainda no dístico-exemplo de Tibulo II, 2, 21-2, sem o latim langue e, por via de consequiência, parole, podem-se acumular quantos /t/ se queiram, que não se obterá efeito algum! Supera-se a aparente contradição entre as naturezas do verso e da língua desta forma: a natureza do verso é a analogia, a natureza da língua é a arbitrariedade, mas como se vê, é sobre a base já firmemente estabelecida na arbitrariedade desta, que se podem construir as analogias daquele.

É necessário sublinhar que as condições métricas do verso latino, quais sejam, hexâmetro, pentâmetro, dátilo, espondeu, cesura, ictus, seqüência final, e o que mais for, são ocorrências inúteis fora do sistema que lhes deu origem, e essa é nossa crítica aos procedimentos que buscam exteriorizar os processos internos da langue, capazes de gerar os artefatos de Poética e métrica, em traduções que não levam em conta tais fatos e a identidade cultural dos textos traduzidos e, ainda assim, insistem em chamar-se "traduções".

\section{BIBLIOGRAFIA}

BRODSKY, J. O filho da civilização. In: Menos que um. Trad. Sérgio Flaksman. São Paulo, Cia. das Letras, 1994.

CICÉRON, Pro Archia poeta. In: DELTOUR, F. M. T. Ciceronis orationes. Paris: Delalain, s/d. v. 1. CRYSTAL, D. Dicionário de lingüística e fonética. Trad. M. C. Pádua Dias. Rio de Janeiro, Jorge Zahar,

1988.

DESBORDES, F. Concepções sobre a escrita na Roma antiga. Trad. F. M. L. Moretto e G. M. Machado.

\footnotetext{
${ }^{6}$ Para citar apenas dois momentos, de tudo quanto se disse sobre a importância da contribuição da poesia para a língua de um povo, vejam-se estes: A poesia é o resultado supremo de toda a língua [...] (BRODSKY, op. cit., p. 74) e Praesertim quum omne olim studium atque omne ingenium contulerit Archias ad populi romani gloriam laudemque celebrandam? ("Precisamente quando Árquias já contribuiu com todo seu esforço e todo seu talento para celebrar a glória e o louvor do povo romano?"- CICÉRON, Pro Archia poeta, IX, in: DELTOUR, s/d, p. 455).
} 
São Paulo, Ática, 1990.

FÓNAGY, I. Le langage poétique: forme et fonction. In: BENVENISTE, É et al. Problèmes du langage. Paris, Gallimard, 1966.

GREIMAS, A. J., COURTÉS, J. Dicionário de semiótica. Trad. A. D. Lima et al. São Paulo, Cultrix, 1983.

GUIMARÃES ROSA, J. Ficção completa. Rio de Janeiro, Nova Aguilar, 1994. v. 1.

GUIRAUD, P. Problèmes et méthodes de la statistique linguistique. Paris, PUF, 1960.

HJELMSLEV, L. Essais linguistiques. Paris, Minuit, 1971.

HUIZINGA, J. Homo ludens. São Paulo, EdUSP/Perspectiva, 1971.

JAKOBSON, R. Lingüística e poética. In: Lingüística e comunicação. 12 ed. Trad. I. Blikstein e J. P. Paes.

São Paulo, Cultrix, 1985.

PERINI, G. B. Fondamenti di metrica. In: TRAINA, A., PERINI, G. B. Propedeutica al latino

universitario. Bologna, Pàtron, 1982.

TIBULLE. Tibulle et les auteurs $d u$ Corpus Tibullianum. Texte établi et traduit par M. Ponchont. Paris, Les

Belles Lettres, 1950.

TODOROV, T. Os gêneros do discurso. Trad. E. A. Kossovitch. São Paulo, Martins Fontes, 1980. 